\title{
Antibiotics Susceptibility Patterns of some Uropathogens to Nitrofurantoin and Nalidixic Acid among Pregnant Women with Urinary Tract Infections in Federal Medical Centre, Bida, Niger-State, North Central, Nigeria
}

\author{
Akobi Oliver Adeyemi, ${ }^{1, *}$ Emumwen Evbaziegbere Gideon ${ }^{1}$, Inyinbor Henry Eromosele ${ }^{1}$, \\ Akobi Evelyn Chimerenma ${ }^{2}$, Ogedengbe Sunday Oladokun ${ }^{\text {, }}$, Uzoigwe Eunice Ogochukwu ${ }^{1}$, \\ Abayomi Rachel Olufunmilayo ${ }^{1}$, Emumwen Ehiosu Favour ${ }^{3}$ \\ ${ }^{1}$ Medical Microbiology Department, Federal Medical Centre, Bida, Niger-State \\ ${ }^{2}$ Nursing Department, Federal Medical Centre, Bida, Niger State \\ ${ }^{3}$ Medical Laboratory Services, Fed. Polytechnic Medical Centre, Bida, Niger-State \\ *Corresponding author: oliverant2006@yahoo.com
}

Received July 15, 2014; Revised July 28, 2014; Accepted August 10, 2014

\begin{abstract}
Background: Antimicrobial drug resistance is a worldwide problem that is exacerbated by the diminishing number of new antimicrobial drugs. Developing countries face substantial problems of antimicrobial resistance as a result of emerging and re-emerging resistant organisms. Aim: This study was design to reports on antibiotic susceptibility and resistance pattern of bacteria pathogens of UTIs among pregnant women in Bida, North Central, Nigeria, and to determine the extent of resistance of these bacteria pathogens to these drugs in the community. Materials and Methods: The research was a retrospective studies carried out between August 2012 to December 2013 and were exempted from ethical approval. Five hundred and sixteen (516) bacterial pathogens were selected for this study as isolated at the Medical Microbiology Department of Federal Medical Centre, Bida, Niger State, North Central, Nigeria. Data was coded, computed and analyzed using SPSS version 16.0 and p-values $\leq 0.05$ was considered to be statistically significant. Result: Out of this 516 bacteria isolates, Escherichia coli 342(66.3\%) was the most predominant followed by Staphylococcus aureus 162(31.4\%), Klebsiella specie 6(1.2\%), Serratia marcescens $4(0.8 \%)$ and the least prevalence Proteus specie $2(0.4 \%)$. Overall susceptibility pattern of uropathogens to Nitrofurantoin was (58.5\%) and Nalidixic acid (34.5\%) and both were statistically significant (Nitrofurantoin $\mathrm{p}=0.000$, Mean value 75.5 and Nalidixic acid $\mathrm{p}=0.000$, Mean value 44.5 ). Escherichia coli the highest in predominance shows susceptibility rate of $61.4 \%$ and $42.1 \%$ to Nitrofurantoin and Nalidixic acid respectively. Conclusion: Routine microbiological analysis and susceptibility test should be carried out before administration of drugs to patient. Government should make policy that will discourage over the counter sales and use of antimicrobials without prescription from authorized Medical personnel.
\end{abstract}

Keywords: Antibiotics susceptibility, Uropathogen, Urinary tract infections

Cite This Article: Akobi Oliver Adeyemi, Emumwen Evbaziegbere Gideon, Inyinbor Henry Eromosele, Akobi Evelyn Chimerenma, Ogedengbe Sunday Oladokun, Uzoigwe Eunice Ogochukwu, Abayomi Rachel Olufunmilayo, and Emumwen Ehiosu Favour, "Antibiotics Susceptibility Patterns of some Uropathogens to Nitrofurantoin and Nalidixic Acid among Pregnant Women with Urinary Tract Infections in Federal Medical Centre, Bida, Niger-State, North Central, Nigeria.” American Journal of Epidemiology and Infectious Disease, vol. 2, no. 4 (2014): 88-92. doi: 10.12691/ajeid-2-4-1.

\section{Introduction}

Bacterial antimicrobial drug resistance is a worldwide problem that is exacerbated by the diminishing number of new antimicrobial drugs [1,2,3]. Developing countries face substantial problems of antimicrobial resistance. Contributing factors include those involving the public (e.g. self-medication), prescriber (e.g. misinformation, absence of diagnostic tools) and dispenser (e.g. over the counter use, inadequate storage, use of expired drugs) $[4,5]$. The current discourse on infectious disease and drug resistance, as it affects Sub-Saharan Africa is limited to the pressing problems associated with emerging and reemerging resistant organisms [6,7]. Worldwide, the prevalence of antimicrobial resistance limits the 
therapeutic options for treatment of infections, and increases the social benefit from disease prevention [8].

In Africa, about $90.1 \%$ individuals seek care outside the home, of these, $94.7 \%$ take medicines and $36.2 \%$ receive antibiotics. Of all those who receive antibiotics, $31.7 \%$ do not receive a prescription from a doctor and about $26.4 \%$ obtain antibiotics from an informal dispenser [9].

Evidently, antibiotics are widely and inappropriately used in Africa resulting to antibiotic resistance. This situation impinges on the quality of patient care through its associated mortality, morbidity, and significant economic consequences [10]. The emergence of antimicrobial resistance is primarily due to excessive and often unnecessary use of antibiotics in humans and animals [8,11,12]. Increasing antimicrobial resistance in Africa has been exacerbated by multiple factors.

For instance, misdirected human resource and training policies, weak institutions, and inappropriate structures [13]. Conspicuously, there are no adequate laboratory facilities [14] and enough trained staff to isolate pathogens and perform sensitivity tests so that infectious diseases are treated empirically [15].

The prevalent pathogens of UTIs have been found to be resistant to most chemotherapeutic agents, though the antimicrobial susceptibilities of these pathogens are highly predictable [16].

Development of resistance to these antimicrobial agents in UTI cases will therefore affect future treatment and management of the infection with these drugs. Adequate treatment and control of these conditions need a good knowledge of the bacteria species involved and their susceptibility to antimicrobial agents [17]. In the UK, Trimethoprim or Nitrofurantoin are usually recommended for empirical treatment of episodes of uncomplicated cystitis in the community [18], while parenteral cephalosporin and aminoglycosides are reserved for complicated infections or pyelonephritis [19]. According to the Infectious Diseases Society of America (IDSA) guidelines, the agents used in the treatment of UTI include Fluoroquinolones, Cephalosporins and other $\beta$-lactams with or without $\beta$-lactamase inhibitors and Nitrofurantoin [20]. Treatment of a UTI with an antibiotic to which the organism is resistant results in high rates of microbiologic and clinical failure and leads to additional morbidity and costs [21,22], resistance rates vary geographically [23]. The structure of the female's urethra and vagina makes it susceptible to trauma during sexual intercourse as well as bacteria being massaged up the urethra and into the bladder during pregnancy and/or child birth [24]. Majority of UTIs are not life threatening and do not cause any irreversible damage. However, when the kidneys are involved, there is a risk of irreparable tissue damage with an increased risk of bacteraemia [25]. The emergence of antibiotic resistance in the management of UTIs is a serious public health issue, particularly in the developing world where apart from high level of poverty, ignorance and poor hygienic practices, there is also high prevalence of fake and spurious drugs of questionable quality in circulation [26].

AIM: This current study therefore, reports on antibiotic susceptibility and resistance of bacteria pathogens of UTIs among pregnant women in Bida, North Central, Nigeria and to determine the extent of resistance of these bacteria pathogens to these drugs in the community.

\section{Materials and Methods}

\subsection{Study Population}

The research was a retrospective study carried out between August 2012 to December 2013 and was exempted from ethical approval.

Selection of Isolates: Five hundred and sixteen (516) bacterial pathogens were selected for this study as isolated at the Medical Microbiology Department of Federal Medical Centre, Bida, Niger State, according to the standard bacteriological methods described by Baur et al. [6] and Ebie et al. [7]. The agar diffusion method as described by Baur et al. [6] and Ebie et al. [7] was used. Discrete colonies were inoculated into $5 \mathrm{ml}$ of sterile nutrient broth and incubated at $37^{\circ} \mathrm{C}$ over night. The broth culture was then diluted 1:10 with a freshly prepared nutrient broth to give a count of approximately $10^{5}$ colonies per millimetre. A sterile cotton wool was allowed to soak in the broth culture, squeezed by the side of the bottle before streaking over the sensitivity plates and incubated at $37^{\circ} \mathrm{C}$ for $18 \mathrm{~h}$. Interpretation of results was done using the zone of inhibition sizes. Zones of inhibition of $>13 \mathrm{~mm}$ were considered sensitive and $<13$ mm resistant. Nitrofurantoin $(50 \mathrm{mcg})$ and Nalidixic acid (300 mcg) antimicrobial discs were used. SPSS version 16.0 was used for statistical analysis.

Table 1. Antibiotics Susceptibility Pattern of Bacterial Pathogen to Nitrofurantoin and Nalidixic Acid. ISOLATES NO. OF OCCURENCE NITROFURANTOIN (\%) NALIDIXIC ACID (\%) Escherichia coli 342(66.3 \%) 210(61.4\%) 144(42.1\%) Staphylococcus aureus 162(31.4\%) 84(51.9\%) 28(17.3\%) Klebsiella specie 6(1.2\%) 4(66.7\%) 2(33.3\%) Proteus specie $2(0.4 \%) 00$

Serratia mercescens $4(0.8 \%) 4(100 \%) 4(100 \%)$ Total 516(100\%) 302(58.5\%) 178(34.5\%)

Mean susceptibility = Sum of susceptibility of individual organisms/total no of organisms.

\section{Result}

Five hundred and sixteen (516) bacteria pathogens were used for this study (Table 1). Out of this 516 bacteria isolates, Escherichia coli 342(66.3\%) was the most predominant isolates followed by Staphylococcus aureus 162(31.4\%), Klebsiella specie 6(1.2\%), Serratia marcescens $4(0.8 \%)$ and the least prevalence Proteus specie 2(0.4\%). This bacterial isolates were tested against Nitrofurantoin and Nalidixic acid to determine their antibiotic susceptibility pattern. The in-vitro antibiotics susceptibility of the two [2] common antimicrobial agents is shown in Table 1 . The overall susceptibility pattern of Nitrofurantoin to all the bacteria isolated was (58.5\%) and Nalidixic acid (34.5\%). Escherichia coli the highest in predominance shows susceptibility rate of $61.4 \%$ and $42.1 \%$ to Nitrofurantoin and Nalidixic acid respectively. The susceptibility of Staphylococcus aureus to Nitrofurantoin was (51.9\%) and Nalidixic acid (17.3\%). The susceptibility of Klebsiella specie to Nitrofurantoin was (66.7\%) and Nalidixic acid (33.3\%). Serratia marcescens was (100\%) susceptible to both Nitrofurantoin 
and Nalidixic acid. While Proteus specie was not susceptible to the two [2] antimicrobial agents.

\section{Discussion}

Antimicrobial resistance among uropathogens to commonly used antibiotics is becoming increasing.

This phenomenon is giving clinicians few choices of drugs for the treatment of urinary tract infections [27].

In this research, the overall susceptibility patterns of uropathogens to Nitrofurantoin was (58.5\%) and Nalidixic acid (34.5\%) and both were statistically significant (Nitrofurantoin $p=0.000$, Mean value 75.5 and Nalidixic acid $p=0.000$, Mean value 44.5 ). This report is higher than Mokube et al,(28) who reported overall susceptibility rate of Nitrofurantoin (29.2\%), Onoh et al, [29] reported susceptibility rate of Nitrofurantoin (33.7\%), our report is relatively lower than David et al, (30) in London, who reported susceptibility rate of Nitrofurantoin (94\%) and Okonko et al, [31] reported susceptibility rate of Nitrofurantoin (84.2\%) in Nigeria.

The overall susceptibility pattern of Nalidixic acid (34.5\%) in this present study is lower than Mokube et al, [28] who reported Nalidixic acid (95.8\%) in Buea, South West, Cameroon and Okonko et al, [31] reported Nalidixic acid (60.5\%) at lbadan, South West, Nigeria. The report in this study is higher than Onoh et al, [29] who reported overall susceptibility rate of Nalidixic acid (21.4\%) against all uropathogen in Abakaliki, South East, Nigeria.

In this study, Escherichia coli the highest uropathogen exhibited (61.4\%) and (42.1\%) susceptibility rate to Nitrofurantoin and Nalidixic acid respectively. This report is relatively higher than Kalantar et al, [32], who reported Escherichia coli (29.1\%) susceptible to Nitrofurantoin and Nalidixic acid (18.9\%) susceptible in lran.

Onoh et al, [29] reported Escherichia coli (21.1\%) susceptible to Nitrofurantoin and Nalidixic acid (12.5\%), while Mohemid M. Al-Jebouri et al, [33] had similar report, with Escherichia coli (60\%) susceptible to Nitrofurantoin in lraq. However, this report is contrary to lgwegbe et al, [34] who reported Escherichia coli (100\%) susceptible to Nitrofurantoin and Nalidixic acid respectively. Also, Sevki et al, [35] reported Escherichia coli (95.4\%) susceptible to Nitrofurantoin in Turkey.

Staphylococcus aureus second uropathogen was (51.9\%) susceptible to Nitrofurantoin and Nalidixic acid (17.3\%) susceptible. Our report is lower than Okonko et al, [31] who reported Staphylococcus aureus (72.7\%) susceptible to Nitrofurantoin and Nalidixic acid (36.4\%), Iram et al, [37] reported Staphylococcus aureus (66.7\%) susceptible to Nitrofurantoin and Nalidixic acid (100\%) susceptible.

However, our report is similar to Onoh et al, [29] who reported Staphylococcus aureus (57.7\%) susceptible to Nitrofurantoin in Abakaliki, Nigeria. However, our present report is higher than May Mohammed Ali [44], who reported Staphylococcus aureus not susceptible to Nitrofurantoin. Also, Awonuga et al, [36] and Onuoha et al, [48] both reported Staphylococcus aureus not susceptible to Nalidixic acid.

In this study, the susceptibility rate of Klebsiella species was (66.7\%) susceptible to Nitrofurantoin and Nalidixic acid (33.3\%). This report is higher than Kalantar et al, [32] who reported Klebsiella specie (44.4\%) susceptible to Nitrofurantoin, May Mohammed Ali, [44] reported Klebsiella specie (50\%) susceptible to Nitrofurantoin, Onoh et al, [29] reported Klebsiella specie (25\%) susceptible to Nitrofurantoin and Nalidixic acid (25\%) in Abakaliki, Nigeria. Sevki et al, [35] reported Klebsiella pneumoniae (36\%) susceptible to Nitrofurantoin in Ankara, Turkey, and Das et al, [38] reported Klebsiella specie (2.1\%) susceptible to Nitrofurantoin While Onoh et al, [29] reported Klebsiella specie (25\%) susceptible to Nalidixic acid.

Our report is relatively lower than Awonuga et al, [36] who reported Klebsiella specie (75\%) susceptible to Nitrofurantoin and Nalidixic acid (50\%), Okonko et al, [31] reported Klebsiella specie (85.7\%) susceptible to Nitrofurantoin and Nalidixic acid (71.4\%) and Mohemid M. Aljebouri et al, [33] reported Klebsiella specie (88\%) susceptible to Nitrofurantoin and Nalidixic acid (70\%). However, our report is contrary to Selimuzzaman et al,(43) who reported Klebsiella specie (90\%) susceptible to Nitrofurantoin and Nalidixic acid (100\%) susceptible.

Serratia marcescens was (100\%) susceptible to Nitrofurantoin and Nalidixic acid respectively. Our report is similar to Rahman et al, [49] who reported Serratia marcescens (100\%) susceptible to Nitrofurantoin but higher than Mohemid M. Aljebouri et al, [33] who reported Serratia marcescens (80\%) susceptible to Nitrofurantoin and Nalidixic acid (90\%). However, LinHui et al, [39] reported Serratia marcenscens (2.3\%) susceptible to Nitrofurantoin and Nalidixic acid (11.5\%) susceptible among nosocomial urinary tract infection. Drug resistance is one of the nature's never ending process whereby organisms develop tolerance for new environmental condition. These may be due to preexisting factor in the organisms or it may result from the acquired factor(s). Some naturally susceptible strains of bacteria may acquire resistance [40].

However, in this study, the Proteus specie isolated was not susceptible to both Nitrofurantoin and Nalidixic acid. This finding is in agreement with Stanley et al, [41], who reported Proteus mirabilis not susceptible to Nalidixic acid. Our findings is similar to Das et al, [38] who reported Proteus mirabilis (13.4\%) susceptible to Nitrofurantoin and Onoh et al, [29] reported Proteus specie (20.8\%) susceptible to Nalidixic acid. Our report is contrary to Sevki et al, [35] who reported Proteus specie (100\%) susceptible to Nitrofurantoin, Akinola et al, [42] reported Proteus specie (100\%) susceptible to Nalidixic acid, Selimuzzaman et al, [43] reported Proteus specie (80\%) susceptible to Nitrofurantoin and Nalidixic acid respectively. Also, May Mohamed Ali et al, [44] reported Proteus specie (83.3\%) susceptible to Nitrofurantoin and Nalidixic acid (50\%) susceptible in Karbala.

The overall susceptibility pattern of Nitrofurantoin (58.5\%) and Nalidixic acid (34.5\%) to all isolated clinical uropathogen. This is no doubt a public health concern in Bida, North Central, Nigeria. Karlowsky et al, [45] stated that the increasing antimicrobial resistance in bacteria pathogen is a worldwide concern, and resistance rates vary from country to country (Gales et al, 2002), [46].

The prevalence of antimicrobial resistance among UTI agents is increasing and its treatment has become more complicated due to increasing resistance and empirical 
therapy leading to treatment failures mostly associated with gram-negative bacteria (Blondeau et al, 1999), [47].

\section{Conclusion}

The overall susceptibility rate of Nitrofurantoin (58.6\%) and Nalidixic acid (34.5\%) to all isolated uropathogen is of public health concern in this community. Increasing antibiotic resistance is a burden in health industry and the outcome increases mortality and morbidity rate in health statistics.

It is therefore recommended, that routine microbiological analysis and susceptibility test should be carried out before administration of drugs to patient. Government should make policy that will discourage over the counter sales and use of antimicrobials without prescription from authorized Medical personnel.

Africa, is home of unlawful street drug hawkers and counterfeit drugs. Governments need to make policy to control and eradicate this menace through public enlightenment programmes.

\section{Conflict of Interest}

No conflict of interest.

\section{Acknowledgement}

We sincerely honour Mr Ibrahim Taiwo Adeleke for his assistance in the statistical analysis of the data and advice during the research work.

\section{REFERENCE}

[1] Spellberg B, Powers J.H, Brass E.P, Miller L.G, Edwards J.E (Jr.): Trends in antimicrobial drug development: implications for the future. Clin. Infect. Dis. 2004, 38: 1279-1286.

[2] Talbot G.H, Bradley J, Edwards J.E (Jr.), Gilbert D, Scheld M, Bartlett J.G: Bad bugs need drugs: an update on the development pipeline from the Antimicrobial Availability Task Force of the Infectious Diseases Society of America. Clin. Infect. Dis. 2006, 42: 657-668.

[3] Okonko I.O, Soleye F.A, Amusan T.A, Ogun A.A, Ogunnusi T.A, Ejembi J,: Incidence of Multi-Drug Resistance (MDR) Organisms in Abeokuta, South western Nigeria. Global J. Pharmacol. 2009a, 3 (2): 69-80.

[4] Byarugaba D.K. A,: View on antimicrobial resistance in developing countries and responsible risk factors. Int. J, Antimicrob Agents. 2004, 24: 105-10.

[5] Okeke I.N, Lamikanra A, Edelman R. (1999); Socioeconomic and behavioural factors leading to acquired bacterial resistance to antibiotics in developing countries. Emerg Infect Dis. 1999, 5: 1827.

[6] Okeke I.N, Aboderin O.A, Byarugaba D.K, Ojo K.K, Opintan J.A: Growing problem of multidrug-resistant enteric pathogens in Africa. Emerg. Infect. Dis. 2007, [cited 2009 August 18]. Available from http://www.cdc.gov/EID/content/13/11/1640.htm

[7] Okonko I.O, Donbraye-Emmanuel O.B, Ijandipe L.A, Ogun A.A, Adedeji A.O, Udeze A.O,: Antibiotics Sensitivity and Resistance Patterns of Uropathogens to Nitrofurantoin and Nalidixic Acid in Pregnant Women with Urinary Tract Infections in Ibadan, Nigeria. Middle-East J. Sci. Res. 2009b, 4 (2): 105-109.

[8] Eggleston K, Ruifang Z, Richard J,: The Global Challenge of Antimicrobial Resistance: Insights from Economic Analysis. Int. J. Environ. Res. Public Health, 2010, 7, 3141-3149.
[9] Vialle-Valentin C.E, LeCates R.F, Zhang F, Desta A, RossDegnan D,: Predictors of antibiotic use in African communities: evidence from medicines household surveys in five Countries. Tr. Med Int Health; 2012, 17 (2): 211-222.

[10] Kunin C.M,; Resistance to antimicrobial drugs-a worldwide calamity. Ann Intern Med. 1993, 118: 557-61.

[11] Rao G.G,: Risk factors for the spread of antibiotic-resistant bacteria. Drugs; 1998, 55 (3): 323-30.

[12] Okeke I.N, Laxminarayan R, Bhutta Z.A, Duse A.G, Jenkins P, O‘Brien TF, Pablos MA, Klugman K.P,: Antimicrobial resistance in developing countries: Recent trends and current status. Lancet Infect. Dis. 2005, 5, 481-493.

[13] United States Agency for International Development (USAID), Bureau for Africa, Office of Sustainable Development. The Health Sector Human Resource Crisis in Africa: 2003 An Issues Paper.

[14] Peti Ca, Polage CR, and Quinn T,: Laboratory medicine in Africa: barrier to effective health care. Clin Infect Dis. 2006, 42: 377-382.

[15] Ezeala C.C,: Skilling-up medical laboratory technologists for Higher Roles in Biomedical Sciences: A needs analysis. African Journal of Health Professions Education. 2011, 3 (2).

[16] Okonko, I.O, Ijandipe L.A, Ilusanya A.O, Donbraye-Emmanuel O.B, Ogun A.A, Akanbi O.A, Ejembi J and Faleye T.O.C,: Detection of Urinary Tract Infection (UTI) among Pregnant Women in Oluyoro Catholic Hospital, Ibadan, South-Western, Nigeria. Malaysian J. Microbiol. 2009, (in press).

[17] Elhag, K.M. and Chug T.D,: Bacteriuria in the Arabian Gulf. Arab. J.Med., 1982, 1: 5, 10.

[18] Baerheim A,: Empirical treatment of uncomplicated cystitis. BMJ. 2001, 323: 1197-1198.

[19] Gupta K, Hooton T.M, Stamm W.E, Increasing antimicrobial resistance and the management of uncomplicated community acquired urinary tract infections. Ann Intern Med, 2001, 135: 4150.

[20] Johnson J.R, Schaeffer A.J, Stamm,: Guidelines for the treatment of uncomplicated acute bacterial cystitis and acute pyelonephritis in women. Clin Infect Dis; 1999, 29: 74558.

[21] McNulty C.A.M, Richards J and Livermore D.M,: Clinical relevance of laboratory reported antibiotic resistance in acute uncomplicated urinary tract infection in primary care. $J$ Antimicrob Chemother; 2006, 58:1000-8.

[22] Alam M.F, Cohen D and Butler C,: The additional costs of antibiotics and re-consultations for antibiotic-resistant Escherichia coli urinary tract infections managed in general practice. Int $J$ Antimicrob Agents; 2009, 33: 255-7.

[23] Zhanel G.G, Hisanaga T.L and Laing N.M, (2006) Antibiotic resistance in Escherichia coli outpatient urinary isolates: final results from the North American Urinary Tract Infection Collaborative Alliance (NAUTICA). Int J Antimicrob Agents; 27: 468-75.

[24] Kolawale A.S, Kolawale O.M and Kandaki-Olukemi Y.T,: Prevalence of Urinary Tract Infections among Patients Attending Dalhatu Araf Specialist Hospital, Lafia, Nasarawa State, Nigeria," International Journal of Medical Sciences, 2009, Vol. 1, No. 5, pp. 163-167.

[25] Hvidberg H, Struve C, and Krogfelt K.A,: Development of a Long-Term Ascending Urinary Tract Infection Mouse Model for Antibiotic Treatment Studies, Antimicrobial Agents and Chemotherapy, 2000, Vol. 44, No. 1, 2000, pp. 156-163.

[26] Mohemid M. Al-Jebouri, and Salih A. Mdish,: Antibiotic Resistance Pattern of Bacteria Isolated from Patients of Urinary Tract Infections in Iraq. Open Journal of Urology, 2013, Vol. 3, pp. 124-131. Published Online May 2013 (http://www.scirp.org/journal/oju).

[27] Assefa A, Asrat D, Woldeamanuel Y, G/Hiwot Y, Abdella A, Melesse T: Bacterial profile and drug susceptibility pattern of urinary tract infection in pregnant women at Tikur Anbessa Specialized Hospital Addis Ababa, Ethiopia. Ethiopia Medical Journal, 2008, 46: 227-235.

[28] Mokube MN, Atashili J, Halle-Ekane GE, Ikomey GM, Ndumbe PM,: Bacteriuria amongst Pregnant Women in the Buea Health District, Cameroon: Prevalence, Predictors, Antibiotic Susceptibility Patterns and Diagnosis. PLoS ONE 2013, 8 (8): e71086.

[29] Onoh R.C, Umeora O.U.J, Egwuatu V.E, Ezeonu P.O, Onoh T.J.P, Antibiotics sensitivity pattern of uropathogens from pregnant women with urinary tract infection in Abakaliki, Nigeria. Journal of infection and drug resistance, 2013, vol. (6), p. 225-233. 
[30] David C. Bean, Daniel Krahe, David W. Wareham,: Antimicrobial resistance in community and nosocomial Escherichia coli urinary tract isolates, London 2005-2006, Annals of clinical microbiology and antimicrobials, 2008, vol. (7): 13.

[31] Okonko I.O, Donbraye-Emmanuel O.B, Ijandipe L.A, Ogun A.A, Adedeji A.O, and Udeze A.O,: Antibiotics sensitivity and resistance patterns of uropathogens to Nitrofurantoin and Nalidixic acid in pregnant women with urinary tract infections in Ibadan,Nigeria. Middle East Journal of Scientific Research, 2009, 4 (2): 105-109.

[32] Kalantar Enayat, Farhadifar Fariba and Nikkho Bahram,: Asymptomatic Bacteriuria among Pregnant Women Referred to Outpatient Clinics in Sanandaj, Iran. International Braz., J. Urol, 2008, Vol. 34 (6): 699-707.

[33] Mohemid M. Al-Jebouri and Salih A. Mdish,: Antibiotic Resistance Pattern of Bacteria Isolated from Patients of Urinary Tract Infections in Iraq. Open Journal of Urology, 2013, vol. 3, 124-131.

[34] Igwegbe A.O, Ugboaja J.O and Okoli O.A,: Prevalence of asymptomatic bacteriuria among pregnant women in Nnewi, southeast Nigeria. Int. J. Biol. Chem. Sci. 2012, 6 (1): 88-98.

[35] Sevki Celen, Ayla Sargin Oruc, Rana Karayalcin, Sibel Saygan, Serpil Unlu, Belgin Polat and Nuri Danisman,:Asymptomatic Bacteriuria and Antibacterial Susceptibility Pattern in an Obstetric Population. ISRN Obstetrics and Gynecology, 2011, Vol. 2011, Article ID 721872, 4 pages.

[36] Awonuga D.O, Dada-Adegbola H.O, Fawole A.O, Olola F. O, Awonuga O.M and Onimisi-Smith H.O,: Asymptomatic Bacteriuria among an Obstetric Population in Ibadan. WAJM; 2011, 30 (2): 89-93.

[37] Iram Shaifali, Uma Gupta, Syed Esam Mahmood and Jawed Ahmed,: Antibiotic Susceptibility Patterns of Urinary Pathogens in Female Outpatients. North American Journal of Medical Sciences, 2012, Vol., (4) Issue 4.

[38] Das R.N, Chandrashekhar T.S, Joshi H.S, Gurung M, Shrestha N, and Shivananda P.G,: Frequency and susceptibility profile of pathogens causing urinary tract infections at a tertiary care hospital in western Nepal. Singapore Med., J; 2006, 47 (4): 281.

[39] Lin-Hui Su, Jonathan T. Ou, Hsieh-Shong Leu, Ping-Cherng Chiang, Yueh-Pi Chiu, Ju-Hsin Chia, An-Jing Kuo, Cheng-Hsun Chiu, Chishih Chu, Tsu-Lan Wu, Chien-Feng Sun, Thomas V. Riley and Barbara J. Chang,: Extended Epidemic of Nosocomial
Urinary Tract Infections Caused by Serratia marcescens. J. Clinical Microbiology, 2003, p. 4726-4732.

[40] Onifade, A.K., Omoya F.O and Adegunloye D.V,: Incidence and control of urinary tract infections among pregnant women attending antenal clinics in government hospitals in Ondo State, Nigeria. J. Food, Agric. Environ., 2005, Vol. 3 (1): 37-38.

[41] Stanley Chukwudozie Onuoha and Kayode Fatokun,: Prevalence and antimicrobial susceptibility pattern of Urinary Tract Infection among pregnant women in Afikpo, Ebonyi State, Nigeria. American Journal of Life Sciences; 2014, 2 (2): 46-52.

[42] Akinola B. Ajayi, Charles Nwabuisi, Abiodun P. Aboyeji, Nanji S. Ajayi, Adeola Fowotade and Olurotimi O. Fakeye,: Asymptomatic Bacteriuria in Antenatal Patients in Ilorin, Nigeria. Oman Medical Journal, 2012, Vol. 27, No. 1: 31-35.

[43] Selimuzzaman A.B M, Ullah M.A and Haque M.J,: Asymptomatic Bacteriuria during Pregnancy:Causative Agents and Their Sensitivity in Rajshahi City. The Journal of Teachers Association RMC, Rajshahi, 2006, 19 (2): 66-69.

[44] May Mohamed Ali,: Evaluation of antimicrobial susceptibility \& rapid urine screening tests in asymptomatic urinary tract infection in pregnant women in Karbala. Karbala Journal of Pharmaceutical Sciences. 2011, Number 2.

[45] Karlowsky J.A, Jones M.E, Thornsberry C, Critchley I, Kelly L, Sahm D,: Prevalence of antimicrobial resistance among pathogens isolated from female outpatients across the US in 1999. Int. J. Antimicrob. Agents. 2001, 18: 121-127.

[46] Gales A.C, Sader H.S and Jones R.N,: Urinary tract infection trends in Latin American hospitals: report from the SENTRY antimicrobial Surveillance program (1997-2000). Diagn. Microbiol. Infect. Dis. 2002, 44: 289-299.

[47] Blondeau J.M and Tillotson G.S,: Formula to help select rational antimicrobial therapy (FRAT): its application to community and hospital-acquired urinary tract infections. Int. J. Antimicrob. Agents. 1999, 12: 145-150.

[48] Onuoha Stanley Chukwudozie and Fatokun Kayode: Prevalence and antimicrobial susceptibility pattern of Urinary Tract Infection (UTI) among pregnant women in Afikpo, Ebonyi State, Nigeria. American Journal of Life Sciences; 2014, 2 (2): 46-52. (http://www.sciencepublishinggroup.com/j/ajls).

[49] Rahman Farjana, Chowdhury Sadia, Rahman Majibur Md., Ahmed Dilruba and Hossain Anowar,: Antimicrobial Resistance Pattern of Gram-negative Bacteria Causing Urinary Tract Infection. S. J. Pharm. Sci. 2009, 2 (1): 44-50. 